\title{
PRIORITIZATION OF K-12 SCHOOL MAINTENANCE CONSTRUCTION PROJECTS USING GENETIC ALGORITHM AND DYNAMIC PROGRAMMING MODELS
}

\author{
SUBMITTED: March 2020 \\ REVISED: March 2021 \\ PUBLISHED: March 2021 \\ EDITOR: Esther Obonyo \\ DOI: $10.36680 /$ j.itcon.2021.007 \\ Tariq Shehab, Professor \\ California State University, Long Beach, USA \\ Tariq.shehab@csulb.edu \\ Reza Haghighat, Research Assistant \\ California State University, Long Beach, USA \\ haghighat1065@gmail.com \\ Kiran K Sajjan, Research Assistant \\ California State University, Long Beach, USA \\ Kiran.SajjanBallekatteThippeswamy@student.csulb.edu \\ Vahid Balali, Assistant Professor \\ California State University, Long Beach, USA \\ Vahid.balali@csulb.edu
}

\begin{abstract}
High quality education standards and safe learning environments are the fundamental goals of most educational systems. One step towards achieving these goals is to keep existing school facilities in good working conditions through continues repair and maintenance programs. Due to limited resources, efficient use of allocated funds is necessary. This paper presents an optimization tool using Genetic Algorithm (GA) and Dynamic Programming (DP) that manages the expenses of $K-12$ school rehabilitation projects. These models help to find the optimum solutions among the given data through mutations and crossover in deriving a possible solution to a multi-layered problem. The proposed optimization tools maximize the benefits of $K-12$ school repair projects, and focus primarily on serving at-risk students, including those who come from low-income families. To demonstrate the use and capabilities of the proposed tool, a case study is presented. The results revealed by the case study show high potential for better management of school rehabilitation projects and better provision of service to disadvantaged students.
\end{abstract}

KEYWORDS: K-12, Schools Rehabilitation; Resource Management; Optimization; Genetic (GA) Algorithm; Dynamic Programming (DP), budgeting

REFERENCE: Tariq Shehab, Reza Haghighat, Kiran K Sajjan, Vahid Balali (2021). Prioritization of K-12 School Maintenance Construction Projects Using Genetic Algorithm and Dynamic Programming Models. Journal of Information Technology in Construction (ITcon), Vol. 26, pg. 112-127, DOI: 10.36680/j.itcon.2021.007

COPYRIGHT: () 2021 The author(s). This is an open access article distributed under the terms of the Creative Commons Attribution 4.0 International (https://creativecommons.org/licenses/by/4.0/), which permits unrestricted use, distribution, and reproduction in any medium, provided the original work is properly cited. 


\section{INTRODUCTION}

The poor condition of K-12 school buildings has been reported by many practitioners and researchers. The American Society of Civil Engineers has evaluated major infrastructure components, and has assigned school facilities a $\mathrm{D}^{+}$grade (ASCE 2017). This evaluation was performed considering capacity, condition, funding availability, future needs, operation and maintenance, public safety, resilience and innovation (ASCE 2017). It is depicted that there is a $\$ 270$ billion-dollar shortage in the collective budgets of the school districts in the United States by 2020 (ASCE 2017). School facilities may significantly hamper the environment of the classroom or even be unsafe for the students. A budget of at least $\$ 200$ billion would be needed to repair all of the schools in the United States, but much less than this amount has been received for educational infrastructure maintenance (Jimenez 2019, ASCE 2009, 2013, 2017). Hence, there is lack of prioritization systems to maximize the available funds, the needs of the end users, and the severity of the pertinent rehabilitation projects.

To improve the state of K-12 school buildings, researchers previously developed a prioritization model to pinpoint renovation needs of schools (Shahab and Noureddine 2013). The systemic utilization of limited resources and the elimination of subjective judgments regarding school's renovation were performed. Their research focused on the aggregated scores of school building conditions, which were calculated using the Analytical Hierarchy Process (AHP). Despite the fact that it was considered an improvement to current renovation practices, it considered each school facility as one large project that could not be subdivided. This limitation did not accommodate mixed repair strategies and did not allow for component comparison between schools and facilities. Mixed repair strategy is used to address specific components, such as electrical systems in a school "A", while addressing different components, such as a mechanical system, in a school "B". Focusing on the sub-level repair requirements of school buildings can improve the macro level of K-12 educational systems. Accordingly, an optimization program needs to be developed to offer optimal selections to the rehabilitation projects within limited budget environments. The objective of this optimization effort should be to maximize the quality of the K-12 educational system.

The quality of the K-12 educational system may be measured by many parameters. These parameters usually vary, depending on local governments and/or school districts. Many researchers have studied many of these variations, and concluded that the quality of education is best measured through the consideration of the number of served students, specially those with minority backgrounds (Cheng and Tam, 1997, Shwarts and Stiefel (2004), Ladd and Loeb, 2014). Among the highest addressed minority students in many educational systems, who are in need for more allocated resources to help them to excel in their academic programs, are those who come from low income families and/or are described as English Language Learners (ELL) (Cheng and Tam (1997) (Jimenez-Castellanos and Rodriguez (2009) (Education Law Center (2013).

It should be noted that California is among the largest States preferred by many immigrant families whom their children may fall within these two categories and may confront with lower academic readiness in their grade level (Shwarts and Stiefel (2004). Jimenez-Castellanos and Rodriguez (2009) elaborated on the necessity of more funds for ELLs and those who come from low income families to reduce the great variations in student achievements. They also indicated that there are evidences that indicate provision of sufficient funding for minority and low income students will improve the overall students' performance in public schools. Furthermore, they called for the development of a proper resource allocation model which adequately meets the needs of California students and promotes California K-12 educational achievements (Hagighat 2015).

To improve the quality of educational systems and make students more successful, school districts need to consider equity rather than equality (Ramirez et al. (2013). While equity is to provide each student adequate resources, depending on their needs, equality is to provide the same resources to all students, regardless of their needs. There are two types of equity, horizontal and vertical. While the horizontal one focuses on all students in the same situation and gives them equal share of school funding, the vertical targets students with unequal needs and provide equal opportunity for success. It should be noted that the equity concept has been supported by many researchers and educational system officials (Banicki and Murphy (2014)). This approach will ensure the provision of sufficient resources, consideration of variations in student needs, and will lead to a more balanced outcome of the entire educational system. It should be noted that although the earlier trend of policy makers was to provide the same resources to everyone, this trend has changed in the past 2 years (Banicki and Murphy 2014).

In order to consider the equity in California, one approach is to use the Weighted Student Formula (WSF) (Petko It et al. 2005). This approach allocates resources to schools depending on the student's characteristics (e.g. English 
language skills). It considers the actual student's demographic information and fairly distributes budgets among schools. Not only California uses these kinds of school budget formulas, but over 40 other States are doing the same (Toutkoushian and Michael 2008). Many researchers found a high rate of equity within limited resource environments using WSF approach (Miles and Roza 2006). The idea of WSF is to suggest a baseline amount of funds, and to increase it on the basis of additional needs to various division of students in a school, such as English Language Learners (ELLs) and from low income family students.

Various building components are considered in Table 1 to arrive at the best optimum solution for allocating funds (Shahab and Noureddine 2013, Noureddin 2010). These building components receive different percent weightage. The building component receiving the highest percentage is of the highest priority. Likewise, when the factors governing the elements of the building gets the highest percentage, then that particular school receives the complete budgeted cost.

Table 1: Weight of Building Components

\begin{tabular}{|l|l|l|}
\hline Building Components & Weight & Subsequent characteristic from FIT \\
\hline Structural Damage & $46.46 \%$ & Structural Damage \\
\hline Vertical Enclosures & $11.39 \%$ & Windows/Doors/Gates/Fences \\
\hline Horizontal Enclosures & $8.96 \%$ & Roofs \\
\hline Hazardous Material & $5.02 \%$ & Hazardous Material \\
\hline Pest Control & $4.53 \%$ & Pest/Vermin Infestation \\
\hline Fire Protection & $4.30 \%$ & Fire Safety \\
\hline Equipment & $3.60 \%$ & Playground/School Grounds \\
\hline Occupant Support Plumbing & $3.37 \%$ & Sewer \\
\hline Electrical & $2.52 \%$ & Electrical \\
\hline HVAC & $2.32 \%$ & Mech/HVAC \\
\hline Overall Cleanliness & $2.02 \%$ & Overall Cleanliness \\
\hline Restrooms & $1.72 \%$ & Restrooms \\
\hline Interior surfaces & $1.49 \%$ & Interior Surfaces \\
\hline Process Support Plumbing & $1.23 \%$ & Gas Leaks \\
\hline Drinking Fountains & $1.09 \%$ & Drinking Fountains \\
\hline
\end{tabular}

Table 2 represents the various categories considered to get the best optimistic approach during the disbursements of funds based on the criticality of the buildings (Shahab and Noureddine 2013, Noureddine 2010). The more categories considered, the more optimistic the solution is to determine which school should receive the funding.

Table 2: School Facility Hierarchy System.

\begin{tabular}{|c|c|c|c|c|c|}
\hline Equipment & Shell & Interiors & Services & Structure & Special Construction \\
\hline & \multirow[b]{2}{*}{ Horizontal } & $\begin{array}{l}\text { Interior } \\
\text { Construction }\end{array}$ & Plumbing & & \multirow[b]{2}{*}{ Drinking Fountains } \\
\hline & & $\begin{array}{l}\text { Pest Control } \\
\text { Restroom }\end{array}$ & $\begin{array}{l}\text { Occupant Support } \\
\text { Plumbing } \\
\text { Process Support Plumbing }\end{array}$ & & \\
\hline & \multirow[b]{2}{*}{ Vertical } & Interior finishes & HVAC & & \multirow[b]{2}{*}{ Hazardous Material } \\
\hline & & $\begin{array}{l}\text { Overall } \\
\text { Cleanliness }\end{array}$ & Electrical & & \\
\hline
\end{tabular}




\section{PRIORITIZATION METHODS}

Facility Inspection Tool (FIT) utilizes the CSI (Construction Specification Institute) UniFormat. This standard is widely used to provide consistency in economic evaluation of commercial and institutional building projects in the United States and Canada. In order to determine the extent of faults in each element, the FIT uses a scale of 0 to 100. In addition, to derive a percentage on overall rating of a school, the FIT utilizes a simplified mean result of known numbers for every element. The schools are ranked accordingly based on the ranking assigned from the poorest to the finest condition. However, the investment for the rehabilitation of HVAC systems are expensive, therefore, the decision makers of the project are unwilling to assign budget for high-priced amenities until catastrophic failure of such equipment. This leads to prolonged delay of the project opting to wait until the systems ceases to function rather than replacing it (Shahab and Noureddine 2013, Noureddine 2010). To overcome this problem, researchers have suggested the use of the Knapsack approach, optimization algorithms and dynamic programing.

\subsection{Knapsack Problems}

The Knapsack problem, or a Rucksack problem, is categorized as a combinatorial optimization problem (Corman et al. 2009). In this method, the idea is to find the finest among the given set of items, each with a defined weight, value, and mass to make use of the highest possible value. The problem often arises in resource allocation where there are financial constraints. It has attained noteworthy considerations in the field of programming not only on behalf of its abundant applications in resolving optimization problems, but also for its potentiality and ease to be performed as a tool in numerous optimization systems. There are two variations of Knapsack problems: (1) unbounded Knapsack problems, which are used when items are dividable and continuous; and (2) 0-1 Knapsack problems (or exact K-item problem) which are used when items are undividable and discrete (Corman et al. 2009).

\subsection{Optimization Algorithms}

One of the most common solutions for exploring complex optimization problem is through Evolutionary Algorithms (EA). Deriving from natural observations of existing mutation processes paved way for the development of EA. Various pools of populations or solution sets named chromosomes are considered for experimentation. This process conducts repeated selection and manipulation of chromosomes to determine the best set of data. In order to improve subsequent generations, various criteria are undergone such as optimal selection of chromosomes followed by continuous crossover and mutations. To achieve better average performances, these algorithms select random data sets and channels that particular data's activities. A fitness model, which defines the goal of the optimization system, in each generation will assess the conformity and properness of each candidate chromosome in the population (Karaman, et al. 2012). It should be noted that the topmost three types of EAs are evolutionary programming, Genetic Algorithms (GAs), and evolutionary strategies. Between these three types of algorithms, genetic algorithm has been used more often by the researchers and is more popular than the other two (Karaman, et al. 2012).

One similar exploration of GA is based on Darwinian evolutionary theory and has been utilized to address complex optimization problems. This helps in finding a solution by encrypting a chain of possible solutions and maximize the fitness function by running a program in a smaller number of iterations. Encoding solutions or a set of chromosomes is the basic fundamental functions of GA. The method includes calculation of a fitness function value for that set of chromosomes by selecting a part of prior solutions followed by crossover and mutations (Xilin and Shiming 2013). (Orabi and El-Rayes 2012) used GA for their optimization model in transportation rehabilitation projects. They discussed that in optimization of rehabilitation projects, the decision maker needs to confront three main contests of multi-objective optimization problem with respect to nature, nonlinear and noncontinuous planning objectives, and the size of search space. Moreover, they concluded that GA is one of the most practical and powerful methods to solve this sort of problem. Goel et al. 2010 used GA for their resource allocation model. They utilized GA to solve a combination of three different fitness models at the same time using different processors, to both cut the runtime and find the concurrent optimal solution. Huang et al. (2010) used also GA to develop an optimization model for Resource allocation in large construction project. They compared the efficiency of different optimization techniques, such as DP, Linear Programming and GA. Their conclusion was in favor of GA. 


\subsection{Dynamic Programming}

DP is a technique in which a set of choices are examined to solve optimization problems by designing and analyzing an algorithm to find an optimal solution (Hillier and Lieberman 2001). DP helps find a solution for the given problem by splitting an enormous problem into minor sub-problems by connecting the solutions to these sub-problems. Unlike linear programming, DP is used when the overlapping of sub-problems occurs and when individual sub-problem return in various phases of the solving process but do not follow any common mathematical formulas. The increase in efficacy of DP has been proven when the possibility of each individual sub-problems has a solution obtained through various sets of choices. Each of the sub-problems are solved one single time, then solutions are saved and stored in order to avoid repeated processing of that sub-problem.

DP could be applied to solve optimization problems that involves continuous or not continuous data sets (Kruger and Hattingh 2014). It should be noted that finding a solution to problem involving non-continuous datasets adds more complication to the algorithm. It should also be noted that DP has the ability to solve discrete optimization problems such as 0-1 Knapsack problem as a very popular problem when the optimal solution needs is limited to integer numbers

The complicated Knapsack problems could be solved through DP. As the run time over input values is polynomial and run time over input lengths is exponential, Knapsack problems are pseudo-polynomial. The higher run time search over the search space could be evaded through DP by removing the subset of the solutions and storing them, and making use of it as base solution for following procedures will help to find the best optimal solution. Rong and Figueira (2012) proved that the best approach to solve a tedious Knapsack problem is by utilizing DP. Since a large Knapsack problem has a gigantic set of possible solutions, DP increases efficiency by solving a minor central area of problems as principal solutions and then expanding that core by finding new solutions based on the obtained principal solutions. This would significantly lessen the duration of repeated iterations and computational efforts to obtain an optimal solution.

\section{GAPS IN THE KNOWLEDGE AND THE OBJECTIVE OF THIS PAPER}

The competency and proficiency of the current school funding system is debated in many aspects (Brown 2015). Some of the deficiencies involved may include allocating rehabilitation budgets based on first-come-first- served basis (Brown 2015, Haghighat 2015, Noureddin 2010, Shehab and Nouredddin 2013). Furthermore, it has been documented that the allocation of many of these budgets is heavily dependent on the personal judgment of decision makers within school districts, such as Superintendents, School Boards, etc., which may lead to improper distribution of educational resources (Rubenstein et al. 2007).

To improve this current condition, many researchers and industry practitioners have called for the development of more reliable budget allocation systems (Jimenez-Castellanos 2010). Studies have also shown that there is a great disparity in allocation of resources across schools within a school district and argue that resource allocation needs to follow a system that leads to equity of available resources for all different groups of students, including English Language Learners, students from socioeconomically disadvantaged families, and minorities (ELC 2013, Iatarola and Stiefel 2003).

In an effort to respond to this call for development of reliable budget allocation systems, researchers have proposed multiple ones (Abu Thohir, et al., 2017, Shehab and Nouredddin 2013, Chan 2014, Pukite and Geipele 2017, DHS and FEMA 2013). Although the developed systems have improved the budget allocation process in many ways, they were associated with many limitations. These limitation include failing to consider the limitations of budgets and scarcity of available resources; consideration of few selective building components such as roofs, windows and doors, rather than consideration of the entire school building components, such as those considered in the FIT report; targeting and improving the school building sustainability aspects only; missing major safety components, such as fire protection and Hazardous materials, from their priority improvement list; focusing on residential buildings only, which do not include components that are associated with school buildings, such as playgrounds.

This paper presents an optimization model to allocate budgets to school rehabilitation projects within a school district. The proposed model provides a balanced and fair selection tool to school rehabilitation projects. It maximizes the quality of K-12 educational systems, and aims to achieve a better selection of the projects when the available resources are insufficient to accomplish all required rehabilitation projects. An objective function is formulated based on the increase in the overall equity of a limited accessible fund while addressing the differences 
in demands of various categories of students. The proposed model fulfills the needs raised by earlier researchers and many school districts, and further builds on earlier developments of the authors. A case study will be presented to demonstrate the use and capability of the proposed system.

\section{METHODOLOGY}

The objective of this study is to build a model to modify the existing subjective process of decisional procedures to an objective function which will increase the advantage to have a superior habituated amenity for every student from various communities and classification in a school sector. This model achieves the most viable selection of desirable school facility projects on a constrained accessible budget. The anticipated optimization model considers the significance of each individual parameter in a school facility (Shahab and Noureddine 2013, Noureddine 2010). It additionally considers the significance of increasing overall benefit to every student (including minorities and socio-economically disadvantaged students) among the school district on a confined budget.

In order to obtain a solution to the optimization problems, techniques such as GA and DP are applied. The GA model is built with a combinatorial fitness model which includes per capita expenditure of every student, including minority and low-income family students. The limitation of the model is a constrained fiscal budget accessible for school amenities in a school district. With a different approach of solving the problem, the hypothesis of DP in unravelling 0-1 Knapsack problems is implemented to prepare an optimization model based on budget constraint and objective function. To arrive at the precise solution of the DP technique with the utilization of GA, the quantity of primary population and generations should be considered in a large size for the prior set up. This will altogether expand the run time of the program.

The results retrieved from either method are reliable. Nonetheless, the results of the DP in the present definition of the given problem is increasingly precise because of the controlled number of generations considered for GA to reduce the run time of the program. Interestingly, for the future examinations when the setup of the problem changes, the GA technique will be increasingly adaptable to integrate more variables and constraints with a various arrangement of input data.

To develop the proposed optimization model, an objective function has been formulated that increases the overall equity among students. As described earlier in the introduction, there are there are two types of equity, horizontal $\left(E q_{h}\right)$ and vertical $\left(E q_{v-E L L}\right.$ and $\left.E q_{v-L I}\right)$. While the horizontal equity factor $\left(E q_{h}\right)$ considers the total number of students in a school, the vertical equity factors $\left(E q_{v-E L L}\right.$ and $\left.E q_{v-L I}\right)$ focus on the English language learners (ELL) and low income minority students (LI). These equity factors are mathematically expressed as shown in Equations (1), (2), and (3), respectively (Haghighat 2015).

$\mathrm{Eq}_{\mathrm{h}}=\frac{\text { Number of all Students in the school }}{\$ \text { amount of the facility project }}$

$\mathrm{Eq}_{\mathrm{v}-\mathrm{ELL}}=\frac{\text { Number of English language learner students in the school }}{\$ \text { amount of the facility project }}$

$\mathrm{Eq}_{\mathrm{v}-\mathrm{LI}}=\frac{\text { Number of Low Income Family students in the school }}{\$ \text { amount of the facility project }}$

To address the importance factor of these two categories of students, as was suggested by researchers and described in the introduction, the following two coefficients will be considered in the objective function: $\alpha=$ Coefficient of importance for ELL students $\quad$ and $\quad \beta=$ Coefficient of importance for low income family students. It should be noted that these two coefficients are the same as the coefficients that each State uses in its Weighted Student Formulas (WSF), discussed earlier, and could be assigned by decision makers and policy makers. It should also be noted that their values are always greater than one. These coefficients are calculated in accordance to the percentage of ELL and students who came from low income families within each school district (Haghighat 2015). If this percentage is less than 55\%, then they are calculated using Equation 4, otherwise Equation 5 is used. 


$$
\begin{aligned}
& \alpha=\beta=1+\left\lfloor\frac{\text { Number of English language learners and economically disadvantaged students }}{\text { Total enrolled }}\right\rfloor X 0.2 \\
& \alpha=\beta=1+\left(\begin{array}{c}
\left.\left[\frac{\text { Number of English language learners and economically disadvantaged students }}{\text { Total enrolled }}\right] X 0.2\right]+[ \\
\left.\left.\mid \frac{\text { Number of English language learners and economically disadvantaged students }}{\text { Total enrolled }}-0.55\right\rceil X 0.5\right\rceil
\end{array}\right)
\end{aligned}
$$

To accommodate mixed repair strategies and allow transitions from one component to another between school buildings, with an aim to improve the overall K-12 educational service, the importance of each school building component needs to be considered. In doing so, an earlier work of the authors was utilized (Shehab and Noureddine 2013). In this work, school repair projects were broken down into six components using the Uniformat system, and their importance factors were calculated using the AHP technique. These components are; structure, shell, interior, services, equipment and special construction. The weights of these components are; $46.5 \%, 20.4 \%, 9.8 \%$, $13.7 \%, 3.6 \%$, and $6.1 \%$, respectively.

In consideration of the equity factors, the importance of disadvantage students, and the importance weights of school building components, the objective function of the proposed optimization model was formulated as:

Objective Function:

$$
\mathrm{O}=\left\{\left[\mathrm{N}_{\text {Imp }}\right] \mathrm{Eq}_{\mathrm{h}}\right\}+\left\{\alpha \times\left[\mathrm{N}_{\text {Imp }}\right]\left[\mathrm{Eq}_{\mathrm{v}-\mathrm{ELL}}\right]\right\}+\left\{\beta \times\left[\mathrm{N}_{\text {Imp }}\right]\left[\mathrm{Eq}_{\mathrm{v}-\mathrm{LI}}\right]\right\}
$$

Constraints:

$$
\begin{aligned}
& \mathrm{N}_{\text {Imp }}<1 \\
& \alpha>1 \\
& \beta>1 \\
& \mathrm{Eq}_{\mathrm{h}}<1 \\
& \mathrm{Eq}_{\mathrm{v}-\mathrm{ELL}}<1 \\
& \mathrm{Eq}_{\mathrm{v}-\mathrm{LI}}<1
\end{aligned}
$$

Where,

$\left(\mathrm{N}_{\text {Imp }}\right)$ are the weights of school components

$\left(\mathrm{Eq}_{\mathrm{h}}\right)$ is horizontal equity,

$\left(\mathrm{Eq}_{\mathrm{v}-\mathrm{ELL}}\right)$ is vertical equity for language proficiency,

$\left(\mathrm{Eq}_{\mathrm{v}-\mathrm{LI}}\right)$ is vertical equity for low-income family students.

$\alpha$ is the coefficient of importance for English language learners

$\beta$ is the coefficient of importance for low-income family students

Since the variables of this objective function describe the quality of K-12 educational systems, the goal will be to maximize it. Maximizing it will increase the equity for all students, meet the additional demands of minority students, and consider the important factors associated with different school building components. The constraints on this objective function will be defined by the users in accordance to budget availability. It should be noted that $\left[\mathrm{N}_{\mathrm{Imp}}\right],\left[\mathrm{Eq}_{\mathrm{h}}\right],\left[\mathrm{Eq}_{\mathrm{v}-\mathrm{ELL}}\right]$, and $\left[\mathrm{Eq}_{\mathrm{v}-\mathrm{LI}}\right]$ are all vector. While the size of $\left[\mathrm{N}_{\mathrm{Imp}}\right]$ is [1 6], all other sizes vary depending on the size of every school district.

To optimize the above formulated objective function, a number of techniques could be utilized, among which is GA. GA was used by many researchers to optimize rehabilitation projects and allocate resources in the construction industry (Karaman, et al. 2012), (Xilin and Shiming 2013), (Orabi \& El-Rayes 2012), Goel et al. (2010).

The optimization model is developed in MATLAB and is solved with both GA and DP approaches. The input data needs to be saved in text document, or Microsoft Excel spreadsheet. The number of columns is the same for every district, but the number of rows will vary with the number of schools within the district. The output budgets correspond to the initial order of the schools in the input file respectively. Therefore, it is important to keep the order unchanged for the correct interpretation of the output. A sample format of the input data is shown in Table 3.

A school district could determine the cost of each category of rehabilitation projects. The total cost of the projects needs to be defined for a fiscal year, and the scope of the projects could be reclassified to meet the proposed categories. Data for six categories of rehabilitation projects could be reclassified as the proposed structure which 
is shown in Figure 2 (Shahab and Noureddine 2013, Noureddine 2010). Therefore, the cost of each scope of facility projects in a school district will be added to the correspondent category and the total amount of budget needed for that category will be calculated.

Table3: Input Data Format

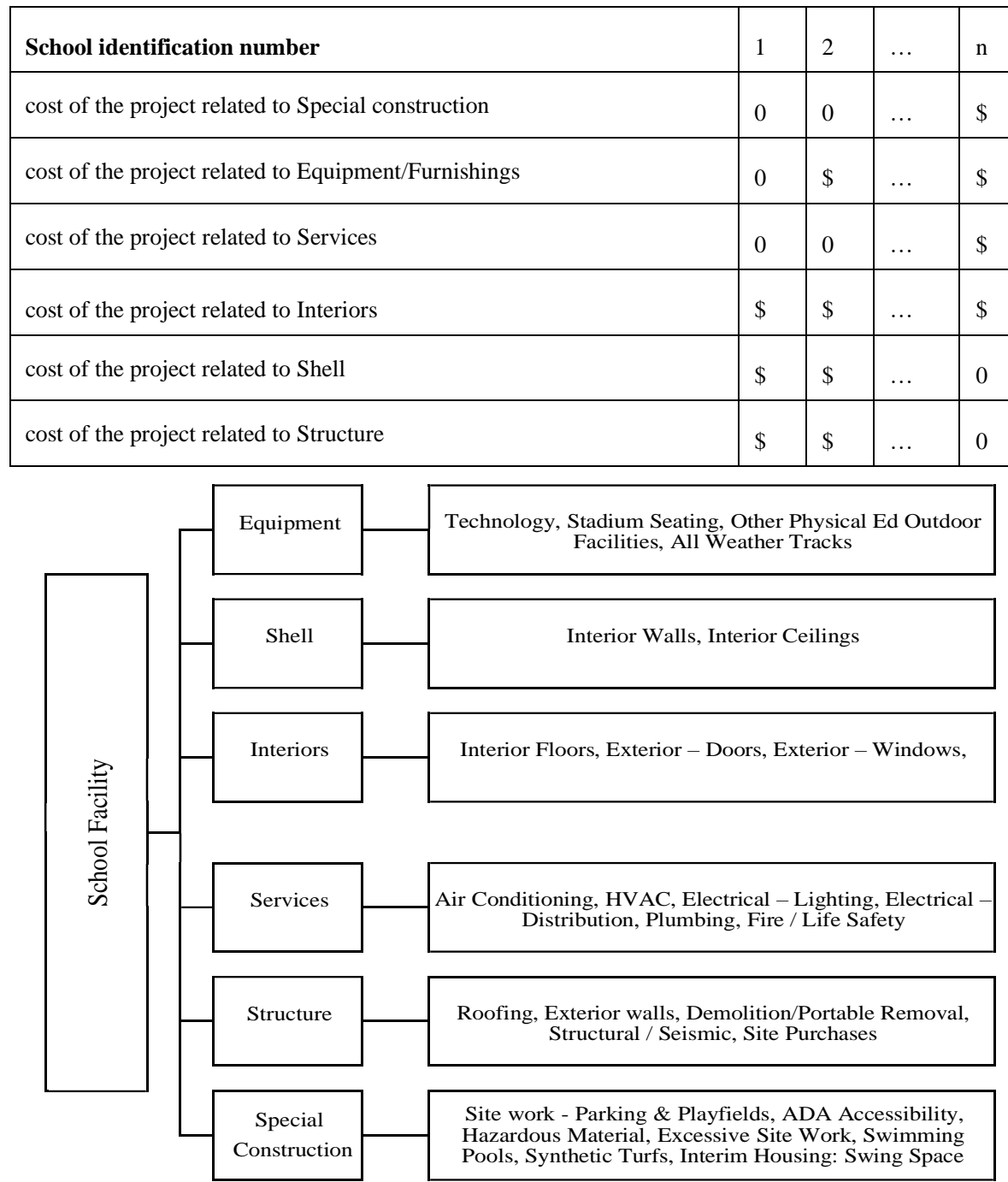

Figure 2: Proposed structure for reclassification of the facility projects.

The output of the program will be a table containing the costs corresponded to the projects. There will be some projects which are funded based on their defined cost in the input, and there will be some projects which are not funded since the resources are limited. The correspondent fund of these projects in the output will be 0 . A sample format of the output data is shown in Table 4.

The program is designed to give the two options of GA and DP as a method of solving the problem. In the first screen of the program, a short description about GA and DP is given to the user and the user needs to select one of the methods (See Figure 3(a)). When the user selects the optimization method another screen will open automatically and asks for the important coefficients of English Language Learner students, Low-Income Family students, the total number of schools in the school district, and the amount of available budget in the school district for funding the projects (See Figure 3(b)). After the user enters the values and pushes the Next Step button, another screen will pop up and with a short description of input format, and prompt the user to upload a text file with 9 columns (See Figure 3(c)). At the final step, in a new screen the user needs to hit the run button to start the optimization analysis (See Figure 3(d)). The optimal solution of the program will be shown in the MATLAB workspace and can be exported to any spread sheet file. 
Table 4: Output of Optimization Model

\begin{tabular}{|l|l|l|l|l|}
\hline School identification number & $\mathbf{1}$ & $\mathbf{2}$ & $\mathbf{l}$ & $\mathbf{n}$ \\
\hline Number of Low-Income Family students & No. & No. & No. & No. \\
\hline Number of English Language Learner students & No. & No. & No. & No. \\
\hline Total number of enrolled students in the school & No. & No. & No. & No. \\
\hline cost of the project related to Special construction & $\$$ & $\$$ & $\$$ & $\$$ \\
\hline cost of the project related to Equipment/Furnishings & $\$$ & $\$$ & $\$$ & $\$$ \\
\hline cost of the project related to Services & $\$$ & $\$$ & $\$$ & $\$$ \\
\hline cost of the project related to Interiors & $\$$ & $\$$ & $\$$ & $\$$ \\
\hline cost of the project related to Shell & $\$$ & $\$$ & $\$$ & $\$$ \\
\hline cost of the project related to Structure & $\$$ & $\$$ & $\$$ & $\$$ \\
\hline
\end{tabular}
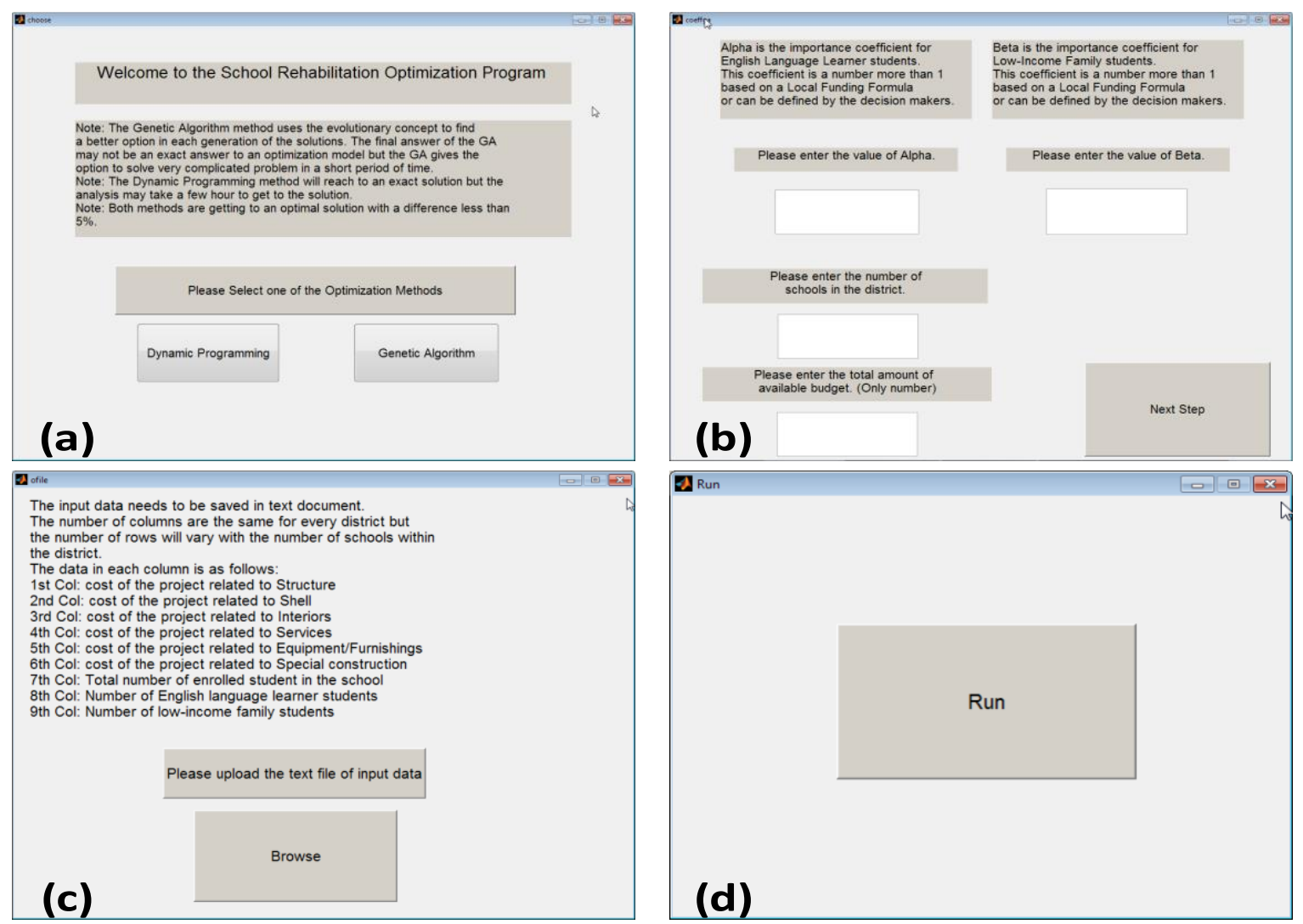

Figure 3: (a)Select the optimization method; (b) Importance coefficients, number of schools, and available budget; (c) Upload the input data; (d) Run the program.

\section{CASE STUDY}

In order to illustrate the efficiency and applicability of the developed model in the real-world cases, a case study is conducted to optimize schools' facility rehabilitation projects in Long Beach Unified School District (LBUSD). Since the effectiveness of the model is better shown in larger school districts with a greater number of schools and facility projects, LBUSD, which rules over a total number of 87 schools is selected. It is thought-provoking that 
even in 2007, LBUSD held community dialog and performed a survey to find out the community opinion on important criteria in prioritizing school facility projects. The criteria used in the questionnaire includes but is not limited to the age of the buildings, number of students, condition of the buildings, and new schools to address overcrowding. The result of the survey shows that $46 \%$ of the voters chose the condition of the building as the most important criteria in prioritization and $21 \%$ of the voters voted for number of students study in the school.

The definition and classification of scope of work in modernization and rehabilitation projects in LBUSD varies to some extent from the categories defined in this study. Therefore, minor modification is applied on the gathered data from the school district to reclassify the tasks and their associated costs. In LBUSD facility master plan, projects are classified in five different categories as follows: (1) New Building; (2) Major Renovation; (3) Moderate Renovation; (4) Minor Renovation; and (5) General Maintenance.

Since the concern of this study is to make an optimization model for rehabilitation projects, construction of new facilities is not considered in the case study. Minor renovations include upgrading of some portion of the building with either repair or replacement of flooring, ceiling, lighting, electrical upgrades, and painting. Moderate and Major renovation projects aim to upgrade the facility to meet the code requirements and future educational program demands. Although the extent of repairs in moderate renovation is narrower than major renovation, they both include the tasks such as handicap accessibility, heating/ventilation/air conditioning, roof, electrical, windows, flooring, ceiling, lighting, technology, infrastructure, and signal system.

LBUSD facility master plan shows that about $74 \%$ of the schools within the district are subjected to a major or moderate renovation because of the condition of the existing buildings. The percentage of each class of facility master plan in LBUSD is shown in Figure 4.

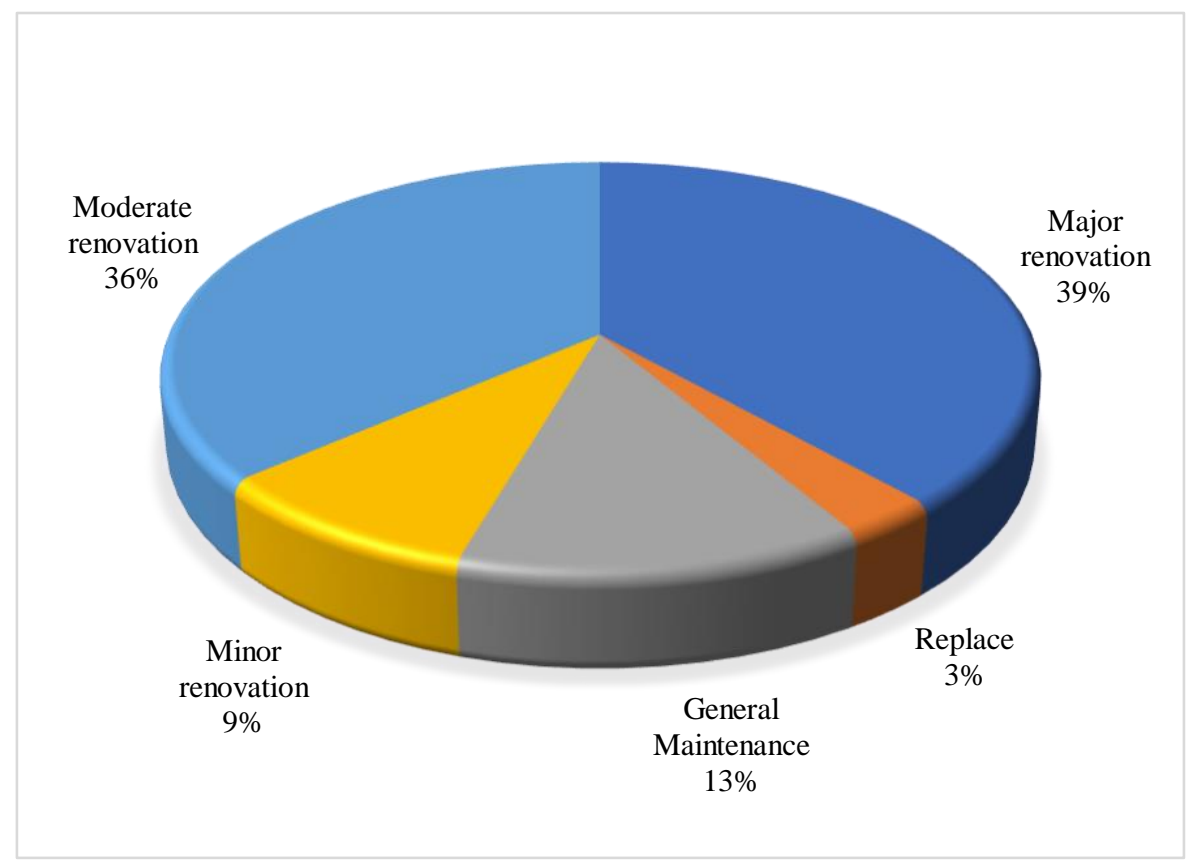

Figure 4: LBUSD facility projects break down.

The items which are typically included in LBUSD facility renovation and maintenance program and the items which are not included are listed as it is shown in Table 5.

The data for facility modernization and maintenance projects in LBUSD is gathered from LBUSD Department of Facilities Development \& Planning, the scope of work for each project is modified to conform to the 6 defined categories in this study. From the data gathered from LBUSD on the current, complete and incomplete renovation and modernization projects the LBUSD renovation items are reclassified to the six categories as it is shown in Table 6. 
Table 5: Included and Not Included Items in LBUSD Facility Master Plan

\begin{tabular}{|c|c|}
\hline Items Typically Included & Items are not included \\
\hline Roofing & Demolition/Portable Removal \\
\hline Exterior - Walls & Hazardous Material \\
\hline Exterior - Windows & Excessive Site Work \\
\hline Exterior - Doors & Structural / Seismic \\
\hline Interior Floors & Site Purchases \\
\hline Interior Walls & Interim Housing: Swing Space \\
\hline Interior Ceilings & Swimming Pools \\
\hline Air Conditioning & Synthetic Turfs \\
\hline HVAC & All Weather Tracks \\
\hline Electrical - Lighting & Stadium Seating \\
\hline Electrical - Distribution & Other Physical Ed Outdoor Facilities \\
\hline Plumbing & Inflation \\
\hline Fire / Life Safety & \\
\hline Technology & \\
\hline ADA: Accessibility & \\
\hline Site work - Parking \& Playfields & \\
\hline
\end{tabular}

Table 6: Projects' Scope Reclassification for LBUSD

\begin{tabular}{|l|l|}
\hline Optimization Model Categories & LBUSD Renovation Projects' Categories \\
\hline Structure & Roofing, Exterior - Walls \\
\hline Shell & Interior Walls, Interior Ceilings \\
\hline Interiors & Interior Floors, Exterior - Doors, Exterior - Windows \\
\hline Services & $\begin{array}{l}\text { Air Conditioning, HVAC, Electrical - Lighting, Electrical - Distribution, Plumbing, } \\
\text { Fire / Life Safety }\end{array}$ \\
\hline Equipment and Furnishes & Technology \\
\hline Special Construction & Site work: Parking \& Playfields, ADA Accessibility \\
\hline
\end{tabular}

Based on the student demographic data from LBUSD, the percentage of English Language Learners and students from Low-Income Families in this district is $69.54 \%$. Therefore, the importance coefficients for adequacy will be calculated for this district as follows:

$\alpha=\beta=1+0.2 \times 0.6954+0.5 \times(0.6954-0.55)=1.21185$

The parameters in the objective function of the model will be:

$\left\{\left[N_{\text {Imp }}\right]\right\}=[0.4646,0.2035,0.0976,0.1373,0.0360,0.0611]$

$\left[E q_{h}=\frac{[\text { Number of Students }]}{\left[\$ \text { Str. }, \$ \text { Shell, } \$ \text { Inter. }, \$ \text { Serv. }, \frac{\$ E q u}{\text { Furn }}, \$ \text { Special Const. }\right]}\right.$ 


$$
\begin{gathered}
{\left[E q_{V-E L L}=\frac{[\text { Number of English Language Learner Students }]}{\left[\$ \text { Str. }, \$ \text { Shell, } \$ \text { Inter. }, \text { \$Serv. }, \frac{\$ E q u}{\text { Furn }}, \$ \text { Special Const. }\right]}\right.} \\
{\left[E q_{V-L I}=\frac{[\text { Number of Low }- \text { Income Family Students }]}{\left[\$ \text { Str. }, \$ \text { Shell }, \$ \text { Inter. }, \$ \text { Serv. }, \frac{\$ E q u}{\text { Furn }}, \$ \text { Special Const. }\right]}\right.}
\end{gathered}
$$

The optimization problem (i.e. Equation 6) is solved with consideration of $\alpha, \beta, N_{I m p}$ and the limited amount of budget defined by user, both with GA and DP. A comparison between the results of these two algorithms is conducted at the end.

\subsection{LBUSD Facility Projects Costs and Student Demographic Data}

The modified data for modernization and maintenance projects in Long Beach Unified School District are available. The cost of the modernization project in each of the six categories has been calculated using the district raw data for the fiscal year of 2013-2014 and dollar amount of each category is rounded up to the nearest thousand. Although there are some completed projects from the last fiscal year, many modernization projects are incomplete and the actual cost of the project has not been determined yet.

\subsection{Results and Discussions}

\subsubsection{GA Solution}

The total amount of budget which is needed to complete all the projects is about $\$ 81$ million dollars. The assumption for available budget in this case study is $\$ 40$ million dollars. The optimal selection of the GA model is interpreted to the cost of each category in each school. After 140 generations, the GA model for this optimization problem reaches the optimum solution. Although the defined number of generations is 1000, changes in the solutions after 140 generations is inconsiderable, and this generation could be picked as the optimal solution of the program.

The average expenditure per all students, the average expenditure per ELL students, and the average expenditure per Low-Income Family students are shown in one graph in Figure 7. The average expenditure is calculated by the sum of selected projects cost in each school and then it is divided by the total number of the students and the number of ELL students and Low-Income Family students in the corresponding school. The average expenditure per ELL students is significantly higher in some schools due to the lower rate of these students in that school.

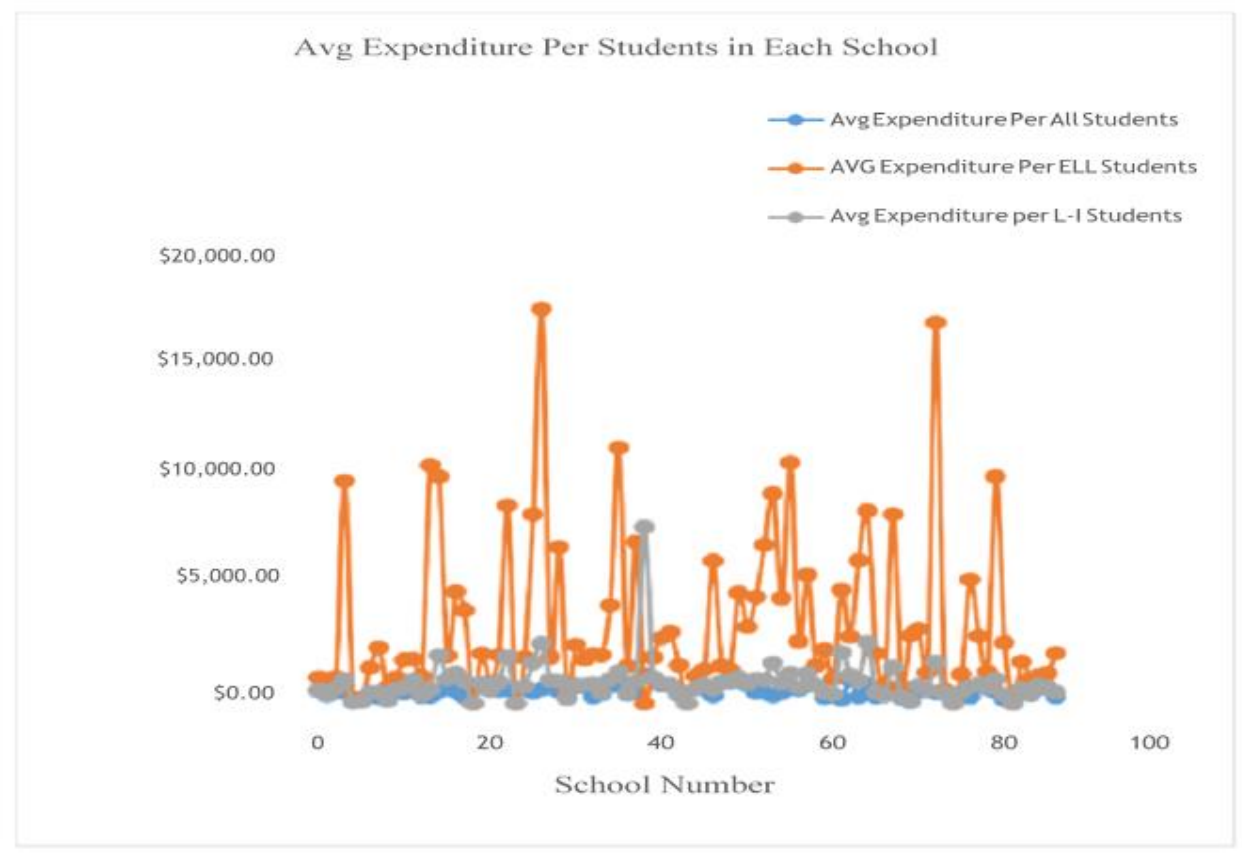

Figure 7: Average expenditure per students in each school in GA solution. 


\subsubsection{DP Solution}

The optimal selection of the DP model is interpreted to the cost of each category in each school. The average expenditure per all students, the average expenditure per ELL students, and the average expenditure per LowIncome Family students from the DP solution are shown in one graph in Figure 8.

\section{Avg Expenditure Per Students in Each School}

$\because$ Avg Expenditure PerAllstudents

$\multimap$ AVG Expenditure Per ELL Students

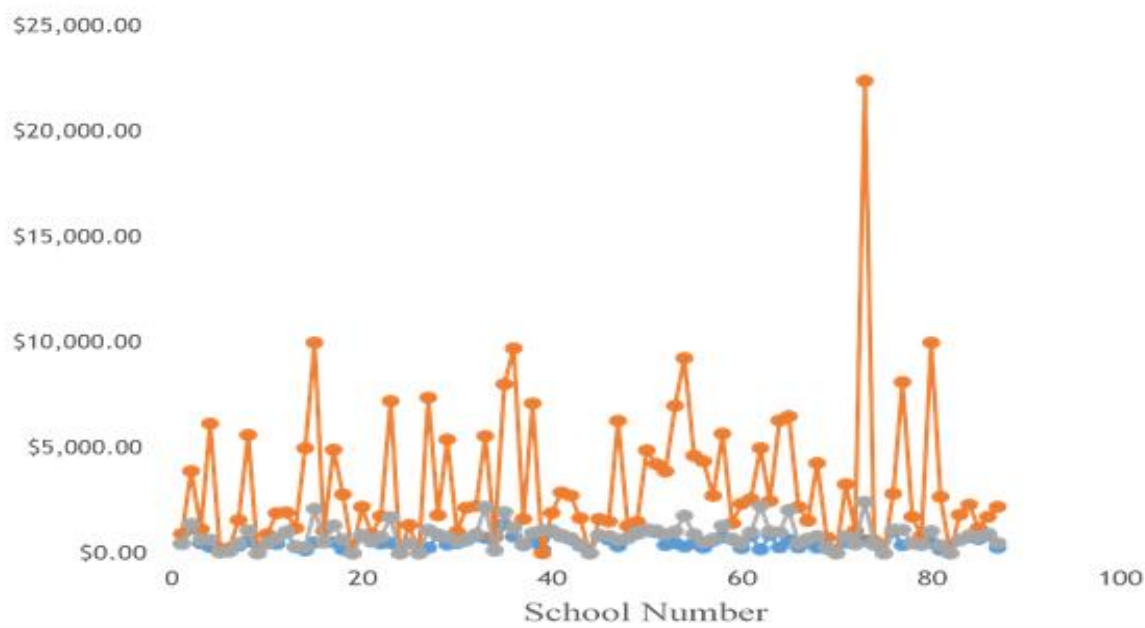

Figure 8: Average expenditure per students in each school in Dynamic Programming solution.

In order to validate the proposed approach, these two models are investigated in a case study for a large urban school district. The GA method answer is very sensitive to the definition of the first population of the data and to the number of iterations in finding new generation of a solution. On the other hand, DP method is very well suited to the current configuration of the problem and although the run time of the program in this method will be longer, it reaches the exact answer at the end.

The sum of the selected projects cost from GA model uses the total available budget of $\$ 40$ million by finding an exact solution to the problem. Both of the methods maximize their fitness function on the output. The value of the fitness function on each method is calculated by the program and it is shown in Table 7.

Table 7: Value of Fitness Functions

\begin{tabular}{|l|l|}
\hline Budget Used in Dynamic Programming & US \$40,000,000 \\
\hline Budget Used in Genetic Algorithm & US \$39,995,000 \\
\hline Genetic fitness function evaluated on Dynamic Programming output & 1.013477 \\
\hline Genetic fitness function evaluated on Genetic output & 1.031773 \\
\hline Knapsack total value evaluated on Dynamic Programming output & $1.393728 \mathrm{e}+005$ \\
\hline Knapsack total value evaluated on Genetic output & $1.353071 \mathrm{e}+005$ \\
\hline
\end{tabular}

The result of both methods is reliable and valid as a solution to the optimization problem; however, the concept of reaching the answer is different for these two methods. The result of these two methods is different in the selection of the projects in schools. However, these differences are not significant. As shown in Table 8, for example, in 
school number 1, Addams Elementary, the GA solution grants the project in Equipment and Furnishing category while this item is not selected by the DP solution. Although DP reaches the exact solution, the program run time is longer than the GA method. Moreover, DP is a suitable method of solving this specific problem. Therefore, if the objective function or the definition of inputs change, the applicability of this method needs to be investigated for the new problem. In contrast, GA method is more flexible to utilize any changes in the objective function and the inputs.

Table 8: Results of GA and DP for School Number 1 Addams Elementary

\begin{tabular}{|c|c|c|c|c|c|c|}
\hline & Structure & Shell & Interiors & Services & Equipment & Special Construction \\
\hline GA & $\$ 140 \mathrm{~K}$ & $\$ 120 \mathrm{~K}$ & $\$ 20 \mathrm{~K}$ & $\$ 190 \mathrm{~K}$ & $\$ 110 \mathrm{~K}$ & $\$ 20 \mathrm{~K}$ \\
\hline DP & $\$ 140 \mathrm{~K}$ & $\$ 120 \mathrm{~K}$ & $\$ 20 \mathrm{~K}$ & $\$ 190 \mathrm{~K}$ & $\$ 0 \mathrm{~K}$ & $\$ 20 \mathrm{~K}$ \\
\hline
\end{tabular}

\section{CONCLUSION}

The quality of school facilities in the United States has always been a primary concern of the government, policy makers, and communities. The complexity of the maintenance and rehabilitation projects, and the limited available resources have provided decision makers with few options for funding the projects. Even though the policy makers have developed Facility Inspection Tools (FIT) to routinely control the condition of the existing facilities and to prioritize the facility repair projects, the suggested system works on a first-come, first-served basis, which does not necessarily guarantee the project with the highest priority receives the proper amount of funding. The present study addresses the aforementioned problem and provides a solution using optimization models based on the concept of equity in available resources. It improves the results of the FIT system and previously developed budget allocation systems developed by researchers. This model finds the optimal solution by accounting for the importance factor of each element of a school facility project. The developed models also address budget limitations and concerns regarding resource distribution decisions within school districts. Further, the importance of resource allocation at the school level is discussed, and the priority of specific categories of students such as English Language Learners and students from Low-Income Families are addressed. Two aspects of horizontal and vertical equity in education are utilized to form the objective function of the optimization model. The goal of the model is to increase equity in both directions at the same time for rehabilitation projects. Optimization solutions are obtained based on GA and DP. The two algorithms are programmed to find the optimal solution within a fiscal year. The result of both methods answered the research problem, were found to be reliable and valid as a solution to the optimization problem; however, the concept of reaching the answer is different for these two methods. The result of these two methods is different in the selection of repair project components within schools. However, these differences are not significant. The developed models will help school districts to better manage their budgets while maximizing the quality of educational system. The developed program provides school districts with an option to input their coefficients for specific categories of students and to choose different amounts of available funds. To run the optimization model, the number of schools and students and the dollar amount of projects in schools are inputted into the program with either an Excel or text file. The result of the optimization model is a table showing the projects that need to be funded and the projects that need to wait for further resources. The proficiency of the system in finding the optimal selection of projects is shown in a case study containing eightyseven schools within LBUSD. The available budget for the case study was half of the total budget to accomplish all projects. Since time is usually an influential parameter on decision making and the proposed models optimize repair projects within one fiscal year, further research needs to be performed to analyze the effects of time in the decision making process. This improvement will be helpful to consider projects that might take more than one fiscal year to be completed.

\section{ACKNOWLEDGEMENT}

The authors acknowledge the Los Angeles Unified School District (LAUSD) Department of Operation and Maintenance and the Long Beach Unified School District (LBUSD) Department of Facilities Development \& Planning for providing data for this research project. 


\section{REFERENCES}

Abu Thohir, M., Sangadji, S. and Assd, S. (2017)." Maintenance and Rehabilitation Prioritization of School Buildings Using Knapsack Problem”, International Journal of Science and Applied Science, 2(1), 236248.

American Society of Civil Engineers (ASCE). (2009). “America's infrastructure report card." <http://www.infrastructurereportcard.org> (Nov. 8, 2014)

American Society of Civil Engineers (ASCE). (2013). "America's infrastructure report card." <http://www.infrastructurereportcard.org> (Oct. 12, 2014)

American Society of Civil Engineers (ASCE). (2017). "America's infrastructure report card." $<$ http://www.infrastructurereportcard.org> (Mar. 12, 2020)

Banicki, G., and Murphy, G. (2014). "Adequacy model for school funding." Research in Higher Education Journal, 23, 1-24.

Brown, Edmund G. (2015). "2015-16 Governor's Budget Summary." California Budget, <http://www.ebudget.ca.gov> (Jan. 15, 2015)

Chan, E. (2014). "Building Maintenance Strategy: A Sustainable Refurbishment Perspective”, 2(1), 19-25.

Cheng, C., and Tam, M. (1997). "Multi-models of quality in education." Quality Assurance in Education, 5(1), 22-31

Corman, T. H., Leiserson, C. E., Rivest, R. L., and Stein, C. (2009). Introduction to algorithms, 3rd Ed., The MIT Press, Cambridge, MA.

Department of Homeland Security (DHS) and Federal Emergency Management Agency (FEMA) (2013), Incremental Seismic Rehabilitation of School Buildings (K-12)", CreatSpace Independent Publishing Platform.

Educational Law Center (ELC). (2013). Funding, formulas, and fairness: what Pennsylvania can learn from other states' education funding formulas, Educational Law Center, Philadelphia.

Goel, T., Stander, N., and Lin, Y.-Y. (2010). "Efficient resource allocation for genetic algorithm based multiobjective optimization with 1,000 simulations." Structural and Multidisciplinary Optimization, 41(3), 421432.

Haghighat, R. (2015). An Optimization Model to Allocate Budget in School Rehabilitation Projects. M.S.thesis, California State University, Long Beach.

Huang, J., Wang, X., and Chen, R. (2010). “Genetic algorithms for optimization of resource allocation in large scale construction project management.” Journal of Computers, 5(12), 1916-1924.

Hillier, F. S., and Lieberman, G. J. (2001). Introduction to operations research, 7th Ed., McGraw-Hill, New York, NY.

Iatarola, P., and Stiefel, L. (2003). "Intradistrict equity of public education resources and performance." Economics of Education Review, 22(1), 69-78.

Jiménez-Castellanos, O., and Rodríguez, J. L. (2009). "Intradistrict resource reallocation for Latino English language learners: an exploratory multiple case study approach." Bilingual Research Journal, 32(3), 298316.

Jimenez, L. (2019). "The Case for Federal Funding for School Infrastructure" <https://www.americanprogress.org/issues/education-k-12/reports/2019/02/12/466104/case-federalfunding-school-infrastructure/> (Sep.18, 2020)

Karaman, S., Shima, T., and Frazzoli, E. (2012). "A process algebra genetic algorithm." Evolutionary Computation, IEEE Transactions on, 16(4), 489-503. 
Kruger, M. F., and Hattingh, J. M. (2014). "A partitioning scheme for solving the 0-1 knapsack problem." ORiON, 19(1), 33-52.

Ladd, H., and Loeb, S. (2014). "The challenges of measuring school quality: Implications for educational equity." Education, Justice, and Democracy, University of Chicago Press, Chicago, IL., 22-55.

LAUSD Budget Services and Financial Planning Division. (2013). "Superintendent's 2013-14 final budget ", Los Angeles Unified School District Board of Education <http://laschoolboard.org> (Oct. 6, 2014)

Long Beach Unified School District (LBUSD). (2008). "Facility master plan" lbschools <http://www.lbschools.net/District/measurek/schoolbuildingplan.cfm> (Dec.3, 2014)

Miles, K. H., and Roza, M. (2006). "Understanding student-weighted allocation as a means to greater school resource equity." Peabody Journal of Education, 81(3), 39-62.

Noureddine, A. (2010). "A prioritization system for school rehabilitation projects." M.S. thesis, California State University, Long Beach.

Orabi, W., and El-Rayes, K. (2012). "Optimizing the rehabilitation efforts of aging transportation networks." Journal of Construction Engineering and Management, 138(4), 529-539.

Petko, M. (2005). "Weighted student formula (WSF): what is it and how does it impact educational programs in large urban districts?" National Education Association, < http://www.nea.org> (Dec. 1, 2014)

Pukite, I. and Geipele, I. (2017). “ Different Approaches to Building Management and Maintenance Meaning Explanation”, Procedia Engineering, 172, 905-912.

Ramirez, A., Siegrist, M., Krumholz, P., and Rainey, T. (2013). "Equity, adequacy, and categorical funding in Colorado school finance: a focus on English language learners." Education and Urban Society, 45(6), 700713.

Rong, A., and Figueira, J. R. (2012). "Computational performance of basic state reduction based dynamic programming algorithms for bi-objective 0-1 knapsack problems." Computers and Mathematics with Applications, Elsevier Ltd, 63(10), 1462-1480.

Rubenstein, R., Schwartz, A. E., Stiefel, L., and Amor, H. B. H. (2007). "From districts to schools: The distribution of resources across schools in big city school districts." Economics of Education Review, 26(5), 532-545.

Schwartz, A. E., and Stiefel, L. (2004). "Immigrants and the distribution of resources within an urban school district." Educational Evaluation and Policy Analysis, 26(4), 303-327.

Shehab, T. and Noureddine, A. (2013). "Prioritization Model for Rehabilitation of Public School Buildings in California", Journal of Construction Education and Research, 10(1), 58-75.

Toutkoushian, R. K., and Michael, R. S. (2008). "The impacts of school funding formula modifications on equity, fiscal neutrality, and adequacy." Journal of Education Finance, 33(4), 352-380.

Xilin, Z., and Shiming, L. (2013). "Optimization model of higher education resources allocation based on genetic algorithm." Management Science and Engineering, 7(3), 76-80. 